\title{
$\gamma$ Ray Dosimetry and Mating Capacity Studies in the Laboratory on Aedes albopictus Males
}

\author{
F. BALESTRINO ${ }^{1,2}$ A. MEDICI ${ }^{1}{ }^{1}$ G. CANDINI ${ }^{3}$ M. CARRIERI ${ }^{1}$ B. MACCAGNANI ${ }^{1}$ M. CALVITTI ${ }^{4}$ \\ S. MAINI, ${ }^{5}$ AND R. BELLINI ${ }^{1,6}$
}

\begin{abstract}
J. Med. Entomol. 47(4): 581-591 (2010); DOI: 10.1603/ME09272
ABSTRACT In Italy, Aedes albopictus Skuse is currently recognized as the most dangerous mosquito, and as currently applied conventional control methods gave unsatisfactory results, we are developing alternative strategies such as the sterile insect technique. To find the optimal sterilizing dose, male pupae were exposed to different doses of $\gamma$ rays in the range $20-80 \mathrm{~Gy}$, generated by a Cesium-137 source. The effects of male pupal age at irradiation and $\gamma$ ray dose on adult male emergence, sterility level, longevity, and mating capacity were evaluated, and dose-response curves of residual fertility were calculated. Radiation tests were also performed on female pupae to observe their reproductive capacity in case of accidental release. Results confirmed that the age at which the male pupa is irradiated is an important factor that affects the longevity of the adult, whereas the effect of age on the induced sterility level is less pronounced. When male pupae older than $30 \mathrm{~h}$ were irradiated, the longevity of the adults was not affected by doses up to $40 \mathrm{~Gy}$. The $40-\mathrm{Gy}$ dose appeared sufficient to induce high level of sterility $(>99 \%)$ at any male pupal age for all the strains tested. The duration of coupling and the number of mated females per male appeared to be affected by the radiation received by male pupae only at doses higher than $40 \mathrm{~Gy}$. The female pupae were more sensitive to radiation than male pupae, with strong reduction in fecundity and fertility at $20 \mathrm{~Gy}$ and complete suppression of oviposition at higher doses.
\end{abstract}

KEY WORDS sterile insect technique, Aedes albopictus, male longevity, residual fertility

In a few years since its introduction into Italy in 1990 (Sabatini et al. 1990), Aedes albopictus has become the most noxious and problematic mosquito species in the country. The colonization process occurred very quickly, mainly though the passive transportation, and this species is currently found in all the Italian territory, including the main islands (ECDC Technical Report 2009). Being an urban, day-biting, exophilic species, its presence strongly limits humans from using outdoor spaces and affects many economic activities. The Chikungunya fever epidemic that occurred in the summer 2007 in the Emilia-Romagna region confirmed its vector competence for arboviruses that cause human disease in temperate regions (Angelini et al. 2007, Bonilauri et al. 2008).

In Italy, current control methods against Ae albopictus (larval control, source removal, community par-

\footnotetext{
${ }^{1}$ Medical and Veterinary Entomology Department, Centro Agricoltura Ambiente "G. Nicoli,"Via Argini Nord 3351, 40014 Crevalcore, Italy.

${ }^{2}$ Current address: International Atomic Energy Agency, Agency's Laboratories, A-2444 Seibersdorf, Austria.

${ }^{3}$ Medical Physics Department, St. Anna Hospital, Ferrara, Italy.

${ }^{4}$ C. R. ENEA-Casaccia, BAS Biotec Agro, Rome, Italy.

${ }_{5}^{5}$ Council for the Research-National Agency for Atomic Energy (DISTA), University of Bologna, Bologna, Italy.

${ }^{6}$ Corresponding author: Medical and Veterinary Entomology Department, Centro Agricoltura Ambiente "G. Nicoli," Via Argini Nord 3351, 40014 Crevalcore, Italy (e-mail: rbellini@caa.it).
}

ticipation) show unsatisfactory results in terms of a sustainable reduction of vector density (data not published). It could be argued that the main reason for the weakness of conventional control practices lies in the eco-ethology of the species that makes it very adaptable to colonize a number of artificial habitats. Larval sites located in private properties make the task of control by public institutions extremely difficult because of limited access to private properties and to the high cost of running such programs. Community participation campaigns to control mosquito breeding sites, even when regularly conducted with professional methods, never achieve a sufficient level of active participation from citizens for tangible results to be seen (unpublished data). For these reasons, in 1999, the Centro Agricoltura Ambiente "G. Nicoli" started to develop a sterile insect technique (SIT) program focused on Ae. albopictus to be included in an integrated control program (Medici et al. 2000, Bellini et al. 2004, 2007).

Several characteristics make Ae. albopictus a suitable candidate for SIT application, as follows: it is a recently introduced species with populations showing a low genetic variability (Urbanelli et al. 2000), it mainly colonizes urban areas while showing low aptitude to establish in rural and natural areas (unpublished data), it has a low active dispersal ability (Hawley 1988, Takagi 1995, Honório et al. 2003), and it is 
relatively easy to manage under mass rearing and artificial conditions (Bellini et al. 2007). Moreover, in temperate areas like northern Italy, the outdoor reproduction is impossible for 5-6 mo and winter survival relies on the eggs entering a state of diapause (Hawley 1988). The naturally high egg mortality brought on by winter results in a very low vector density at the beginning of the favorable season (Carrieri et al. 2008).

The SIT has proven to be a very effective technology and was successful in controlling and/or eradicating important insect pests like the New World screwworm Cochliomyia hominivorax (Coquerel) from the Curaçao Island, Venezuela (Baumhover et al. 1955), from the southern United States, and from Central America (Whitten and Foster 1975, Wyss 2000); Ceratitis capitata (Wiedemann) was also eliminated from South America (Barry et al. 2004) and Glossina austeni Newstead from Unguja island, Zanzibar (Vreysen et al. 2000). In the 1960s-1970s, SIT was applied against several mosquito species, but many important programs were abandoned before their completion because of political controversies (Anonymous 1975, Asman et al. 1981, Curtis 2006).

Our project aims to develop mass rearing methods and sterilization techniques for the production of sterile males of high quality that perform well in terms of longevity, active dispersal, and mating ability in competition with wild-type males for wild virgin females.

The best stage to irradiate mosquitoes to achieve a good sterilization level while minimizing unavoidable loss of fitness in the adult is a controversial subject. The irradiation of Anopheles albimanus male pupae aged $<24 \mathrm{~h}$ by Ali and Rozenboom (1972) demonstrated that the males maintained the capacity of inseminating the females at all the $\mathrm{x}$-ray doses tested (20-80 Gy). Sterilization by radiation is known to have less deleterious effects on Anopheles males when applied on adults rather than on pupae (Andreasen and Curtis 2005); however, Helinski et al. (2006) found no statistically significant differences between Anopheles arabiensis males irradiated as old pupae or adults. It has been demonstrated that the age of the pupae when exposed to $\gamma$ rays strongly affects their sensitivity to radiation in terms of somatic damages and residual fertility. On different mosquitoes species, the irradiation of old pupae produced sterile adult males with better mating performance compared with males obtained from young irradiated pupae (Wijeyaratne et al. 1977, Andreasen and Curtis 2005, Helinski et al. 2006, Helinski and Knols 2008). To our knowledge, no dosimetry study had been previously performed on Ae. albopictus.

The mating performance of the irradiated male by comparison with the wild fertile male are also essential parameters of fitness that we need to maintain in the sterile males.

According to Jones and Wheeler (1965) and Jones (1968), a fertile Aedes aegypti male is able to inseminate five to six females in a short time and is capable of up to 30 matings even when its supply of spermatic fluids is depleted. After the fifth-sixth mating, approx- imately $2 \mathrm{~d}$ are needed to produce new sperm and to regenerate the substances produced by the accessory glands.

To set up an efficient sexing method based on the difference in size between male and female pupae, the rearing protocol was carefully defined and standardized to reduce the size variability as a result of environmental conditions (Bellini et al. 2007). But, because of the overlap in size between sexes, the smallest female pupae remain in the male fraction and are therefore irradiated and released together with the males. It being understood that the elimination of the females remains a fundamental objective, the effects of $\gamma$ ray treatment on female pupae have been estimated to evaluate the possible impact of female impurity on the current pilot sterile mosquito release program.

\section{Materials and Methods}

Mosquito Stocks and Rearing Methods. Three strains of Ae. albopictus collected in three localities in northern Italy (Rimini, Cesena, and Pinerolo) were reared under standard laboratory conditions ( $27 \pm$ $1^{\circ} \mathrm{C}, 85 \% \mathrm{RH}, 12 \mathrm{~h}$ scotophase) for several generations. The adults were kept in Plexiglas cages $(50 \times 50 \times 50$ $\mathrm{cm})$ at density of $\approx 1,500-2,000$ individuals per cage. Cages were supplied with $10 \%$ sugar solution on which mosquitoes fed ad libitum. Bovine blood in sheep intestine was offered weekly using an electrically heated aluminum chamber thermostatically controlled. Females laid eggs in plastic beakers containing dechlorinated water and a strip of white filter paper. After oviposition, the filter paper was removed from the cage and left to dry in a closed plastic container with a saturated solution of potassium sulfate. One week later, the eggs were counted and placed in a 1.0-liter closed bottle with 0.75 liters dechlorinated water, $0.25 \mathrm{~g}$ of Bacto nutrient broth, and $0.05 \mathrm{~g}$ of yeast to stimulate hatching. Larvae were reared at fixed density $(1,333$ larvae/L) in white plastic trays $(41 \times$ $31 \times 11 \mathrm{~cm}$ ) containing 3 liters of dechlorinated water provided with aerators and were fed with a diet consisting of $2.1 \mathrm{mg} /$ larva Friskies dry cat food +0.38 $\mathrm{mg} /$ larva brewer yeast $+0.15 \mathrm{mg} /$ larva Tetramin $(10 \%$ was given on day $1 ; 20 \%$ on day $2 ; 30 \%$ on day 3 ; and $40 \%$ on day 5) (Bellini et al. 2007). To separate males from females at the pupal stage, a mechanical separation method exploiting pupal size dimorphism was employed using a metal sieve with a $1,400-\mu \mathrm{m}$ square hole mesh (Medici et al. 2000).

Irradiation Procedure. An IBL 437 irradiator (CIS Bio International, Bagnols-sur-Cèze, France) was used to conduct experiments. This apparatus, normally used for blood irradiation at the Medical Physics Department of St. Anna Hospital (Ferrara, Italy), includes a $50.9 \mathrm{TBq}$ Cs-137 linear source.

A cylindrical unit, consisting of a lead-lined steel casing, includes an irradiation plate positioned at its periphery, on which the basket (diameter $130 \mathrm{~mm}$; high $290 \mathrm{~mm}$; volume 3.8 liters) containing the products to be irradiated is inserted. 
The sample basket is placed in face of the source and is uniformly exposed by means of continuous rotation during irradiation at a central dose rate of $2.2 \mathrm{~Gy} /$ $\min \pm 3.5 \%$. The dose distribution inside the basket was determined using GAFCHROMIC EBT dosimetric films (International Specialty Products, Wayne, $\mathrm{NJ}$ ). A dose equal to $4 \mathrm{~Gy}$ was delivered, and films, previously calibrated with increasing doses, were digitized to determine the dose distribution. On the digitized images of radiographic films, a profile through the diameter was chosen to obtain dose distribution normalized on the value measured at the center of the image.

Transportation of the male pupae from the rearing facility to the irradiator ( $1 \mathrm{~h}$ each way) was conducted in petri dishes (diameter $12 \mathrm{~cm}$ ) containing water.

\section{Preliminary Trials}

Effect of Male Pupal Age and Radiation Doses on Male Longevity and Female Residual Fertility. Two Ae. albopictus strains (Pinerolo and Rimini), maintained for 21 generations in laboratory conditions, were used in these trials. Pupae from both strains were selected according to the time from pupation and assigned to three age groups: $16-24 \mathrm{~h}, 24-40 \mathrm{~h}$, and $40-48 \mathrm{~h}$. Male pupae were exposed to 40,60 , and 80 Gy. A total of 600 male pupae was irradiated, and 200 male pupae were used as control. After irradiation, samples of 50 male pupae for each radiation dose and age were placed in cages with 50 virgin females $(3 \mathrm{~d}$ old) of the same strain. At least three replications were carried out for each dose and male pupal age group tested.

Fertility of the females mated with the different irradiated male groups was evaluated in comparison with the control. Longevity of the males was recorded by daily counting and removing the deads in the adult cages.

\section{Dosimetry Tests 1}

Effect of Strain and Radiation Doses on Male Longevity, Female Fecundity, and Residual Fertility. Pinerolo $\left(\mathrm{P}_{\mathrm{F} 22}\right)$, Rimini $\left(\mathrm{R}_{\mathrm{F} 23}\right)$, and Cesena $\left(\mathrm{C}_{\mathrm{F} 20}\right)$ strains were used in this experiment. Male pupae all aged $16-30 \mathrm{~h}$ were treated with $\gamma$ rays at doses of $20,30,40$, and $50 \mathrm{~Gy}$. After irradiation, samples of 50 irradiated male pupae were placed in plastic cages together with 50 virgin, nonirradiated females of the same strain. Each radiation dose was replicated twice for each strain used. On day 5 after caging, all females were offered a bovine blood meal. The eclosion rate of the eggs produced was evaluated after the hatching procedure described above. Male longevity was evaluated by recording daily mortality up to day 30 .

As the mechanical sex separation method at the pupal stage led to a residual percentage of females among the male pupae, we also investigated the residual fertility and fecundity of irradiated females. Because mosquito females are known to be more sensitive to radiation than costrain males (Bakri et al.
2005), female pupae aged $16-40 \mathrm{~h}$ were exposed to $\gamma$ rays at 20,30, and $40 \mathrm{~Gy}$. Samples of 50 irradiated female pupae were placed in cages together with 50 nonirradiated males of the same strain with a continuous supply of $10 \%$ sugar solution. The strain used in this trial came from Rimini $\left(\mathrm{R}_{\mathrm{F} 23}\right)$. Four replications were carried out for this test.

\section{Dosimetry Test 2}

Effect of Male Pupal Age and Radiation Doses on Male Longevity, Female Fecundity, and Residual Fertility. Strain $\mathrm{R}_{\mathrm{F} 23}$ male pupae aged $30-40 \mathrm{~h}$ were exposed to 20, 30, 40, and $50 \mathrm{~Gy}$.

After irradiation, three pools of 50 male pupae for each dose were placed in cages with 50 virgin females of the same strain. Nontreated pupae from the same strain were used as controls. The residual fertility was checked by counting the percentage of hatched eggs after the first blood meal. The number of engorged females was recorded to determine the fecundity rate. Male longevity was recorded, as above. Because experimental conditions and procedures were identical, the data obtained from this test were compared with those from the first trial on male pupae $\left(\mathrm{R}_{\mathrm{F} 23}\right)$ aged $16-30 \mathrm{~h}$ to ascertain the relationship between male pupal age and the effects of radiation dose on biological parameters.

\section{Dosimetry Test 3}

Effect of Radiation Dose on Mating Performances. Strain $\mathrm{R}_{\mathrm{F} 23} 30$ - to $40-\mathrm{h}$ male pupae were treated with 30,40 , and $50 \mathrm{~Gy}$. For each radiation dose and for the control, two cages $(30 \times 30 \times 30 \mathrm{~cm})$ were prepared with four adult males aged $>24 \mathrm{~h}$ and 20 virgin females aged $>48 \mathrm{~h}$. Direct observations were conducted for $4 \mathrm{~h}$, during which the number of coupling observed was registered, as well as the duration of the first four couplings. After the 4-h period, all the females were anesthetized and their spermathecae checked microscopically for the presence of sperm: a female was considered mated when at least one spermatheca tested positive for the presence of sperm. Different parameters were considered in males, as follows: insemination capacity (number of mated females/number of males), mating efficiency (number of mated females/number of observed coupling), and mean duration of the first four couplings.

\section{Statistical Analysis}

Male Longevity. Kaplan-Meier survival analysis was used to determine the survival curves of the males from all radiation treatments and strain groups: data sets were compared using the Mantel-Cox log-rank test.

Fecundity and Residual Fertility. Fecundity and residual fertility were investigated and statistically analyzed by means of two-way analysis of variance (ANOVA) on angular transformed frequency data and by the Newman-Keuls test for means separation, 
Table 1. Female residual fertility as function of the male pupa age and male radiation dose

\begin{tabular}{|c|c|c|c|c|c|c|}
\hline $\begin{array}{l}\text { Male pupa age at } \\
\text { irradiation }(\mathrm{h})\end{array}$ & Dose $(\mathrm{Gy})$ & $N$ & No. total eggs & No. larvae & $\begin{array}{l}\text { Hatching } \\
\text { rate }(\%)\end{array}$ & $\begin{array}{c}\text { Corrected hatching } \\
\text { rate }(\%)\end{array}$ \\
\hline \multirow[t]{4}{*}{$16-24$} & 0 & 3 & 1,771 & 1,230 & $74.2 \pm 23.9$ & \\
\hline & 40 & 6 & 1,636 & 22 & $1.18 \pm 2.88$ & $2.23 \pm 5.47$ \\
\hline & 60 & 3 & 790 & 0 & $0.00 \pm 0.00$ & $0.00 \pm 0.00$ \\
\hline & 80 & 3 & 233 & 0 & $0.00 \pm 0.00$ & $0.00 \pm 0.00$ \\
\hline \multirow[t]{4}{*}{$24-40$} & 0 & 6 & 2,732 & 1,773 & $75.2 \pm 23.8$ & \\
\hline & 40 & 6 & 2,272 & 6 & $0.41 \pm 0.70$ & $0.69 \pm 1.08$ \\
\hline & 60 & 3 & 1,629 & 0 & $0.00 \pm 0.00$ & $0.00 \pm 0.00$ \\
\hline & 80 & 3 & 1,113 & 0 & $0.00 \pm 0.00$ & $0.00 \pm 0.00$ \\
\hline \multirow[t]{4}{*}{$40-48$} & 0 & 3 & 922 & 577 & $75.4 \pm 21.6$ & \\
\hline & 40 & 6 & 4,899 & 15 & $0.38 \pm 0.77$ & $0.41 \pm 0.77$ \\
\hline & 60 & 3 & 1,023 & 1 & $0.23 \pm 0.39$ & $0.27 \pm 0.47$ \\
\hline & 80 & 3 & 1,286 & 0 & $0.00 \pm 0.00$ & $0.00 \pm 0.00$ \\
\hline
\end{tabular}

considering the strain and the radiation level as the main factors. Residual fertility rates were corrected with Abbott's correction formula (Abbott 1925).

Dose-Response Curve of Residual Fertility. To determine the dose-response curve, the irradiated male residual fertility was corrected with the fertility registered in the nonirradiated control using Abbott's formula. To obtain a linear relationship between the radiation dose and the residual fertility, a normal equivalent deviates (N.E.D.) transformation of the percentage of hatched eggs (residual fertility) was calculated, whereas the radiation doses were transformed on a $\log _{10}$ base. Regression analyses were run for each of the two male pupal age groups, and the regression lines were compared by means of the parallelism test.

Mating Performances. Data were statistically analyzed through one-way ANOVA, followed by the Newman-Keuls test for mean separation.

\section{Results}

Irradiator Performances. Tests conducted to evaluate the $\gamma$ ray dose distribution inside the exposition canister have demonstrated a central dose rate and a level of dose homogeneity in the irradiation unit compatible with expected values.

\section{Preliminary Trials}

Residual Fertility. Immediate mortality was negligible in all radiation doses tested, and males from all treatment groups emerged normally (data not shown).

All radiation doses resulted in high levels of male sterilization: the residual fertility of females mated with treated males was significantly lower than in females from the control cages $\left(F_{11,36}=26.63\right.$, sum of squares $(\mathrm{SS})=1.37$, mean of squares $(\mathrm{MS})=1.02, P<$ $0.0001)$. In particular, the residual fertility of males irradiated at the highest doses of 60 and $80 \mathrm{~Gy}$ was near or reached $0 \%$ for all the three age groups (Table 1 ). In general, the residual fertility in the case of males irradiated as pupae aged $>24 \mathrm{~h}$, compared to those irradiated at $16-24 \mathrm{~h}$, showed a trend to decrease, although the differences among the groups were not statistically significant (block ANOVA $F_{2,4}=0.59$ and $P=0.59$ ).

The lowest dose used in the test (40 Gy) appeared sufficient to strongly compromise male fertility at any pupal age, with residual fertility ranging from $2.2 \pm$ $5.5 \%$ for pupae aged $16-24 \mathrm{~h}$ to $0.4 \pm 0.8 \%$ for pupae aged $40-48 \mathrm{~h}$.

Male Longevity. The age at which the pupae were irradiated affected the longevity of the derived adults. According to the log-rank test, male pupae treated at 16-24 $\mathrm{h}$ at all three doses (Table 2; Fig. 1A) showed a significantly lower longevity than the control group $\left(\chi^{2}=77.63, \mathrm{df}=3, P=0.00000\right)$, whereas male pupae treated with $40 \mathrm{~Gy}$ at $24-40 \mathrm{~h}$ and $40-48 \mathrm{~h}$ (Fig. 1, B and C) showed no significant difference when compared with the control. At the highest dose (80 Gy), we registered a notable reduction also in the longevity of males irradiated as older pupae $\left(24-40 \mathrm{~h}, \chi^{2}=\right.$ 55.45 , df $=3, P=0.00000 ; 40-48 \mathrm{~h}, \chi^{2}=33.55$, df $=$ $3, P=0.00000)$.

The log-rank test demonstrated that at any radiation dose, the longevity of the males increased with the age of the pupae at the time of irradiation (Table 2). At 40 and $60 \mathrm{~Gy}$, there was no statistically significant difference between the longevity of males obtained from pupae irradiated at $24-40 \mathrm{~h}$ or $40-48 \mathrm{~h}$. Younger

Table 2. Longevity (days) of the males irradiated as pupae at increasing radiation doses

\begin{tabular}{|c|c|c|c|c|c|}
\hline \multirow{2}{*}{$\begin{array}{l}\text { Dose } \\
(\mathrm{Gy})\end{array}$} & \multirow{2}{*}{$\begin{array}{l}\text { Male pupal } \\
\text { age }(h)\end{array}$} & \multirow{2}{*}{ Longevity } & \multicolumn{3}{|c|}{ Log-rank test } \\
\hline & & & $16-24 \mathrm{~h}$ & $24-40 \mathrm{~h}$ & $40-48 \mathrm{~h}$ \\
\hline \multirow[t]{3}{*}{0} & $16-24$ & $22.98 \pm 6.90$ & & 0.96 & 0.08 \\
\hline & $24-40$ & $22.29 \pm 6.86$ & & & 1.04 \\
\hline & $40-48$ & $23.40 \pm 6.19$ & & & \\
\hline \multirow[t]{3}{*}{40} & $16-24$ & $19.97 \pm 8.27$ & & $2.81 * *$ & $3.27 * *$ \\
\hline & $24-40$ & $22.16 \pm 7.62$ & & & 0.39 \\
\hline & $40-48$ & $22.81 \pm 7.08$ & & & \\
\hline \multirow[t]{3}{*}{60} & $16-24$ & $15.31 \pm 7.07$ & & $2.93 * *$ & $3.28 * *$ \\
\hline & $24-40$ & $20.92 \pm 7.30$ & & & 0.50 \\
\hline & $40-48$ & $21.18 \pm 7.56$ & & & \\
\hline \multirow[t]{3}{*}{80} & $16-24$ & $8.64 \pm 7.36$ & & $2.62 * *$ & $3.64 * *$ \\
\hline & $24-40$ & $12.62 \pm 7.86$ & & & $2.08 *$ \\
\hline & $40-48$ & $18.26 \pm 7.90$ & & & \\
\hline
\end{tabular}

Statistical data refer to the comparison among the pupae within each of the four radiation levels, and are to be read along the rows. *, $P<0.05$; **, $P<0.01$. 

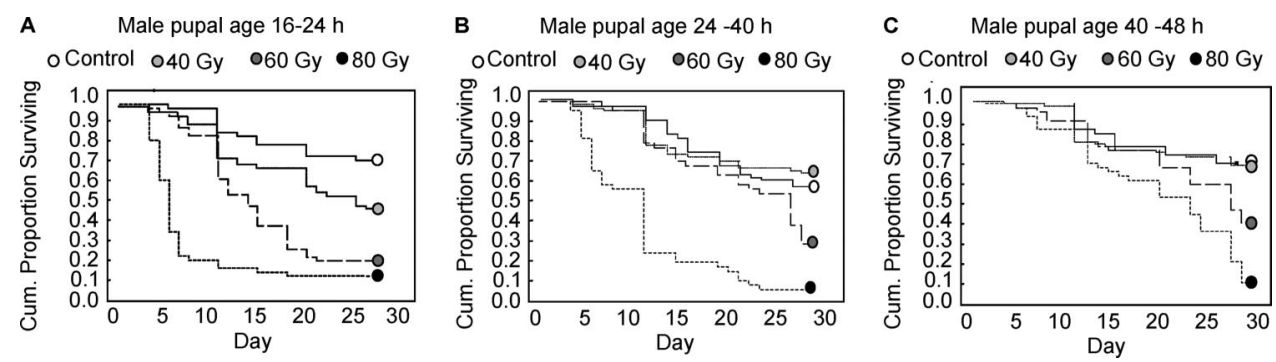

Fig. 1. Adult males' survival after irradiation at different male pupal age (A, 16-24; B, 24-40; C, 40-48 h) at increasing doses compared with nonirradiated males.

pupae $(16-24 \mathrm{~h})$ were more susceptible to radiation treatments. The sensitivity to irradiation as a factor of male pupal age became more pronounced at $80 \mathrm{~Gy}$. There was no difference in longevity among the nontreated groups, showing that the protocol and handling procedures had no measurable effect.

\section{Dosimetry Test 1}

Effect of Strain and Radiation Dose on Male Longevity. Survival analyses (Mantel-Cox log-rank tests) are summarized in Tables 3 and 4.

Among the three tested strains $\left(\mathrm{R}_{\mathrm{F} 23}, \mathrm{P}_{\mathrm{F} 22}, \mathrm{C}_{\mathrm{F} 20}\right)$, Cesena $\left(\mathrm{C}_{\mathrm{F} 20}\right)$ showed a significantly lower survival rate in the untreated control group as well as in the treated groups (Table 3). When comparing Pinerolo $\left(\mathrm{P}_{\mathrm{F} 22}\right)$ and Rimini $\left(\mathrm{R}_{\mathrm{F} 23}\right)$ strains, statistical differences in longevity were registered only at $20 \mathrm{~Gy}$ (Table 3 ). When cumulating data from all the tested strains, differences were observed between the untreated control and the 16- to 30 -h males irradiated at 30,40 , and $50 \mathrm{~Gy}$, whereas no differences were observed between the control and $20 \mathrm{~Gy}$ and between $30 \mathrm{~Gy}$ and $40 \mathrm{~Gy}$ (Table 4).

Table 3. Longevity (days) of adult males of the strains $\mathbf{R}_{\mathrm{F} 23}$, $P_{F 22}$, and $C_{F 20}$ treated as pupae aged 16-30 $\mathrm{h}$ with increasing radiation doses

\begin{tabular}{|c|c|c|c|c|c|c|c|}
\hline \multirow{2}{*}{$\begin{array}{l}\text { Dose } \\
(\mathrm{Gy})\end{array}$} & \multirow{2}{*}{ Strain } & \multirow{2}{*}{ Median } & \multirow{2}{*}{ Mean } & \multirow{2}{*}{ SD } & \multicolumn{3}{|c|}{ Log-rank test } \\
\hline & & & & & $\mathrm{P} 22$ & $\mathrm{R} 23$ & $\mathrm{C} 20$ \\
\hline \multirow[t]{3}{*}{0} & $\mathrm{P}_{\mathrm{F} 22}$ & 29.00 & 26.93 & 5.66 & & 9.07 & $2.40 *$ \\
\hline & $\mathrm{R}_{\mathrm{F} 23}$ & 28.00 & 27.79 & 4.98 & & & $3.46^{* *}$ \\
\hline & $\mathrm{C}_{\mathrm{F} 20}$ & 26.00 & 23.40 & 7.79 & & & \\
\hline \multirow[t]{3}{*}{20} & $\mathrm{P}_{\mathrm{F} 22}$ & 30.00 & 27.71 & 5.90 & & $2.03^{*}$ & $3.13 * *$ \\
\hline & $\mathrm{R}_{\mathrm{F} 23}$ & 31.00 & 25.84 & 8.84 & & & 1.13 \\
\hline & $\mathrm{C}_{\mathrm{F} 20}$ & 31.00 & 23.87 & 10.34 & & & \\
\hline \multirow[t]{3}{*}{30} & $\mathrm{P}_{\mathrm{F} 22}$ & 29.00 & 25.56 & 7.67 & & 1.62 & $3.31 * *$ \\
\hline & $\mathrm{R}_{\mathrm{F} 23}$ & 28.00 & 23.28 & 8.57 & & & 1.36 \\
\hline & $\mathrm{C}_{\mathrm{F} 20}$ & 25.50 & 21.16 & 6.47 & & & \\
\hline \multirow[t]{3}{*}{40} & $\mathrm{P}_{\mathrm{F} 22}$ & 29.00 & 23.29 & 9.60 & & 0.28 & $2.49 *$ \\
\hline & $\mathrm{R}_{\mathrm{F} 23}$ & 28.00 & 23.56 & 8.48 & & & $2.25^{*}$ \\
\hline & $\mathrm{C}_{\mathrm{F} 20}$ & 22.00 & 20.37 & 6.84 & & & \\
\hline \multirow[t]{3}{*}{50} & $\mathrm{P}_{\mathrm{F} 22}$ & 24.00 & 22.28 & 8.18 & & 0.84 & $3.26 * *$ \\
\hline & $\mathrm{R}_{\mathrm{F} 23}$ & 22.00 & 21.41 & 7.67 & & & $2.26^{*}$ \\
\hline & $\mathrm{C}_{\mathrm{F} 20}$ & 19.00 & 17.23 & 8.28 & & & \\
\hline
\end{tabular}

Statistical data refer to the comparison between the strains for each radiation level and are to be read along the row. $*, P<0.05$; **, $P<$ 0.01 .
Effect of Strain and Radiation Dose on Male Residual Fertility. The fecundity of females mated with nonirradiated males was lower for $\mathrm{R}_{\mathrm{F} 23}(48.3 \pm 4.60)$ in comparison with $\mathrm{P}_{\mathrm{F} 22}(65.38 \pm 18.03)$ and $\mathrm{C}_{\mathrm{F} 20}$ $(64.82 \pm 10.61)$ (Table 5). But when analyzing all the data, the strain $\left(F_{4,1}=0.63, \mathrm{SS}=220.9, \mathrm{MS}=220.9\right.$, $P=0.44)$ and the radiation dose received by the male $\left(F_{4,1}=0.83, \mathrm{SS}=292.4, \mathrm{MS}=1,168.7, P=0.52\right) \mathrm{did}$ not affect the fecundity of females. No interaction was found between the two main factors considered $\left(F_{4,1}=1.54, \mathrm{SS}=2,156.8, \mathrm{MS}=539.2, P=0.24\right)$.

The data on male residual fertility for the three strains are reported in Table 5 for all the tested doses. The hatch rate of the eggs laid by females mated with irradiated males was statistically much lower compared with the hatching rate of eggs laid by females mated with nonirradiated males $\left(F_{4,16}=2,277.3\right.$ and $P<0.0001)$. Equally, in all the tested strains $\left(F_{4,8}=\right.$ $3,277.84$ and $P<0.0001$ ), statistical differences were observed in the residual fertility recorded for the females mated with irradiated males at the different doses. In particular, consistent increase (although not significant) in the sterility was observed as the dose received by the male increased from 20 to $50 \mathrm{~Gy}$.

The dose-response curve of residual fertility estimated for the three strains tested is shown in Fig. 2.

The regression lines calculated for the N.E.D. residual fertility in the three strains tested as a function of the dose received by male pupae aged $16-30 \mathrm{~h}$ were depicted by parallel ( $F=2.05$ and $P=0.17)$, but not coincident curves $(F=4.47$ and $P=0.033)$ (Fig. 1$)$. This means that the strains showed similar trends in the function doses received/reduction in fertility, with a slightly different sensitivity. The equations related to the three regression lines were as follows:

Table 4. Longevity (days) of adult males treated as pupae aged 16-30 $\mathrm{h}$ with increasing doses

\begin{tabular}{rcccccccc}
\hline \hline \multirow{2}{*}{$\begin{array}{c}\text { Dose } \\
(\mathrm{Gy})\end{array}$} & Median & Mean & SD & \multicolumn{5}{c}{ Log-rank test } \\
\cline { 5 - 8 } & & & & 0 & 20 & 30 & 40 & 50 \\
\hline 0 & 28 & 25.66 & 6.78 & & 0.40 & $3.48^{* *}$ & $4.56^{* * *}$ & $9.29^{* *}$ \\
20 & 30 & 25.81 & 8.68 & & & $3.09 * *$ & $4.07^{* *}$ & $8.42^{* *}$ \\
30 & 27 & 23.33 & 7.80 & & & & 1.1 & $5.57^{* *}$ \\
40 & 27 & 22.41 & 8.48 & & & & $4.37^{* *}$ \\
50 & 22 & 20.31 & 8.32 & & & & \\
\hline
\end{tabular}

*, $P<0.05 ; * *, P<0.01$. 
Table 5. Fecundity and residual fertility measured in females of $\mathbf{R}_{\mathrm{F} 23}, \mathbf{P}_{\mathrm{F} 22}$, and $\mathrm{C}_{\mathrm{F} 20}$ strains mated with costrain males treated as pupae aged 16-30 $\mathrm{h}$ with $0,20,30,40$, and $50 \mathrm{~Gy}$ (mean $\pm \mathrm{SD})$

\begin{tabular}{|c|c|c|c|c|c|c|}
\hline Strain & Gy & $N$ & No. eggs & No. eggs/female & $\begin{array}{c}\text { No. hatched } \\
\text { larvae }\end{array}$ & Hatching rate $(\%)$ \\
\hline \multirow[t]{5}{*}{$\mathrm{R}_{\mathrm{F} 23}$} & 0 & 2 & $955.0 \pm 606.7$ & $48.3 \pm 34.60$ & $800.0 \pm 486.5$ & $84.7 \pm 2.8 \mathrm{~A}$ \\
\hline & 20 & 2 & $1,768.0 \pm 26.9$ & $91.2 \pm 11.3$ & $97.5 \pm 07.8$ & $5.5 \pm 0.4 \mathrm{~B}$ \\
\hline & 30 & 2 & $1,692.0 \pm 1,301.0$ & $74.3 \pm 36.9$ & $14.0 \pm 0.0$ & $1.2 \pm 0.9 \mathrm{~B}$ \\
\hline & 40 & 2 & $1,843.5 \pm 823.8$ & $73.3 \pm 18.8$ & $3.5 \pm 2.1$ & $0.2 \pm 0.0 \mathrm{~B}$ \\
\hline & 50 & 2 & $1,176.0 \pm 79.2$ & $57.4 \pm 2.1$ & $0.0 \pm 0.0$ & $0.0 \pm 0.0 \mathrm{~B}$ \\
\hline \multirow[t]{5}{*}{$\mathrm{P}_{\mathrm{F} 22}$} & 0 & 2 & $1,648.0 \pm 321.0$ & $65.3 \pm 18.0$ & $1,320.6 \pm 228.2$ & $80.3 \pm 1.8 \mathrm{~A}$ \\
\hline & 20 & 2 & $1,046.5 \pm 296.3$ & $61.5 \pm 17.4$ & $44.0 \pm 11.3$ & $4.2 \pm 0.1 \mathrm{~B}$ \\
\hline & 30 & 2 & $1,130.5 \pm 531.0$ & $49.1 \pm 6.6$ & $27.8 \pm 18.1$ & $2.3 \pm 0.5 \mathrm{~B}$ \\
\hline & 40 & 2 & $1,077.5 \pm 276.5$ & $64.2 \pm 5.1$ & $4.9 \pm 6.9$ & $0.4 \pm 0.5 \mathrm{~B}$ \\
\hline & 50 & 2 & $1,208.0 \pm 585.5$ & $59.5 \pm 4.0$ & $1.4 \pm 2.0$ & $0.1 \pm 0.1 \mathrm{~B}$ \\
\hline \multirow[t]{5}{*}{$\mathrm{C}_{\mathrm{F} 20}$} & 0 & 3 & $1,155.3 \pm 430.0$ & $64.8 \pm 10.6$ & $948.7 \pm 405.1$ & $81.0 \pm 4.8 \mathrm{~A}$ \\
\hline & 20 & 2 & $1,519.5 \pm 111.0$ & $82.0 \pm 2.9$ & $68.5 \pm 0.7$ & $4.5 \pm 0.3 \mathrm{~B}$ \\
\hline & 30 & 2 & $1,290.5 \pm 57.3$ & $75.8 \pm 28.8$ & $5.6 \pm 4.0$ & $0.4 \pm 0.3 \mathrm{~B}$ \\
\hline & 40 & 2 & $1,357.5 \pm 607.4$ & $61.6 \pm 10.0$ & $0.0 \pm 0.0$ & $0.0 \pm 0.0 \mathrm{~B}$ \\
\hline & 50 & 2 & $1,685.0 \pm 468.1$ & $66.9 \pm 14.9$ & $0.7 \pm 1.0$ & $0.0 \pm 0.0 \mathrm{~B}$ \\
\hline
\end{tabular}

A and $B$ indicate statistically significant differences within each strain at $P<0.05$.

1. N.E.D. $\mathrm{R}_{\mathrm{F} 23} 16-30 \mathrm{~h}$ (residual fertility) $=4.35-4.49$ $\left(\log _{10}[\right.$ dose $\left./ \mathrm{Gy}]\right)$

$R^{2}=0.94, F_{1,4}=67.99, P<0.001$, standard error of estimate: 0.16 .

2. N.E.D. $\mathrm{P}_{\mathrm{F} 22} 16-30 \mathrm{~h}$ (residual fertility) $=2.28-2.92$ $\left(\log _{10}[\right.$ dose $\left./ \mathrm{Gy}]\right)$

$R^{2}=0.92, F_{1.4}=45.20, P<0.003$, standard error of estimate: 0.15 .

3. N.E.D. $\mathrm{C}_{\mathrm{F} 20} 16-30 \mathrm{~h}$ (residual fertility) $=3.48-3.98$ $\left(\log _{10}[\right.$ dose $\left./ \mathrm{Gy}]\right)$

$R^{2}=0.91, F_{1,3}=29.10, P<0.01$, standard error of estimate: 0.24 .

Effect of Radiation Dose on Female Fecundity and Fertility. The irradiation of 16- to 30-h-old $\mathrm{R}_{\mathrm{F} 23}$ strain female pupae showed a strong effect in terms of reduction of the fecundity (Table 6$)\left(F_{3,12}=106.47, P<\right.$ $0.001)$. At the lowest dose tested ( $20 \mathrm{~Gy}$ ), the mean number of eggs laid per female $(1.09 \pm 0.96)$ was significantly reduced with respect to the nontreated control (60.74 \pm 11.67$)$, and complete oviposition suppression was registered at 30 and $40 \mathrm{~Gy}$. The fertility of the eggs laid by females irradiated at $20 \mathrm{~Gy}$

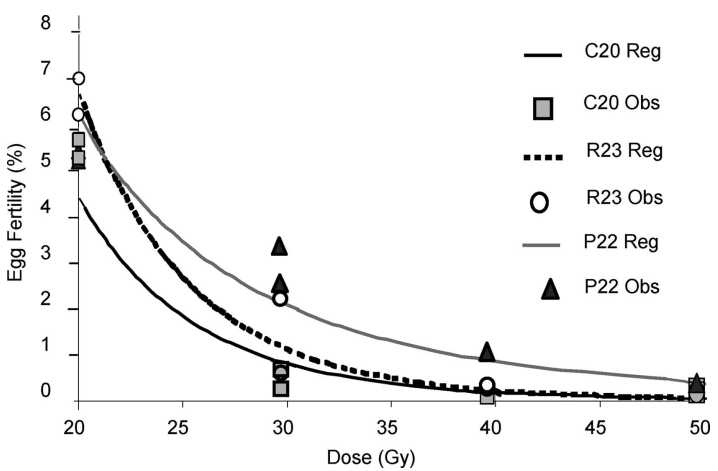

Fig. 2. Dose-residual fertility curve when 16- to 30-h-old male pupae were irradiated for the three strains considered. Lines indicate dose-residual fertility curves, and symbols indicate observed individual values.
$(17.91 \% \pm 18.83)$ was significant lower $\left(F_{1.6}=12.65\right.$ and $P<0.02)$ relative to the control $(76.27 \% \pm$ 18.34 ), and $100 \%$ inhibition of egg hatch was observed at 30 and $40 \mathrm{~Gy}$.

\section{Dosimetry Test 2}

Effect of Male Pupal Age and Radiation Doses on Male Longevity. The analysis of the longevity of males irradiated as pupae aged $16-30 \mathrm{~h}$ and $30-40$ $\mathrm{h}$ spotlighted a relation between the male pupal age at irradiation and the survival of the produced adults. Adult males irradiated as pupae aged 16-30 $\mathrm{h}$ showed a statistically significant lower longevity than nonirradiated males at the radiation doses higher than 20 Gy (Table 7). In addition, the longevity of 16- to $30-\mathrm{h}$ males treated with $50 \mathrm{~Gy}$ was markedly reduced compared with the other dose groups tested (Table 7).

The irradiation of 30- to 40-h-old pupae significantly reduced the longevity with respect to the nontreated control adults at the $50 \mathrm{~Gy}$ dose only, whereas no difference was detected between the males irradiated with 20,30 , and $40 \mathrm{~Gy}$, and the nonirradiated control (Table 7).

Effect of Male Pupal Age and Radiation Doses on Male Residual Fertility. No differences (ANOVA; $F_{411}=0.87$ and $\left.P=0.51\right)$ in fecundity were noted in females mated with males irradiated as pupae $(30-40$ h) at different doses. No differences (block ANOVA; $F_{1,4}=0.41$ and $P=0.56$ ) were also observed comparing the fecundity of the Rimini strain $\left(\mathrm{R}_{\mathrm{F} 23}\right)$ as a function of the male pupa age at irradiation $(30-40 \mathrm{~h}$ versus $16-30 \mathrm{~h})$.

No difference (ANOVA; $F_{1,24}=0.11$ and $P=0.75$ ) in the residual fertility of females mated with males irradiated at $16-30 \mathrm{~h}$ versus $30-40 \mathrm{~h}$ was found. The dose-response curves as a function of male pupa age are shown in Fig. 3. The relative regression lines calculated for the N.E.D. residual fertility of the two irradiated male pupae age groups $R_{\mathrm{F} 23}(16-30 \mathrm{~h})$ and 
Table 6. Fecundity and fertility of females irradiated as pupae aged $16-30 \mathrm{~h}$ with increasing radiation doses

\begin{tabular}{cccccc}
\hline \hline Dose $(\mathrm{Gy})$ & $N$ & $\begin{array}{c}\text { Blood-fed } \\
\text { female }\end{array}$ & No. eggs & No. larvae & No. eggs/female \\
\hline 0 & 4 & $22.7 \pm 1.7$ & $1,368.0 \pm 168.8$ & $1,054.0 \pm 323.0$ & $60.7 \pm 11.7$ \\
20 & 4 & $20.7 \pm 1.9$ & $22.0 \pm 19.72$ & $5.0 \pm 6.4$ & $76.3 \pm 18.3$ \\
30 & 4 & $23.2 \pm 4.4$ & $0.0 \pm 0.0$ & $0.0 \pm 0.0$ & $1.1 \pm 1.0$ \\
40 & 4 & $16.7 \pm 5.1$ & $0.0 \pm 0.0$ & $0.0 \pm 0.0$ & $0.0 \pm 0.0$ \\
\hline
\end{tabular}

$\mathrm{R}_{\mathrm{F} 23}(30-40 \mathrm{~h})$ resulted in parallel $(t=-1.22$ and $P=$ $0.24)$ and coincident curves $(t=0.39$ and $P=0.70)$. The equations related to $\mathrm{R}_{\mathrm{F} 23} 16-30 \mathrm{~h}$ is reported in the previous test (1), while the equation calculated for $\mathrm{R}_{\mathrm{F} 23}$ at $30-40 \mathrm{~h}$ is as follows:

4. N.E.D. $\mathrm{R}_{\mathrm{F} 23} 30-40 \mathrm{~h}$ (residual fertility) $=5.04-4.88$ $\left(\log _{10}[\right.$ dose/Gy])

$R^{2}=0.97, F_{1,9}=259.27, P<0.0001$, standard error of estimate: 0.15 .

\section{Dosimetry Test 3}

Effect of Radiation Intensity on Male Mating Efficiency. The average values of the parameters selected for the assessment of the mating capacity of males treated as pupae aged $30-40 \mathrm{~h}$ with 30,40 , and $50 \mathrm{~Gy}$ are reported in Table 8 together with the statistical analyses.

No statistically significant difference emerged for any of the parameters considered. The data reported in Table 8 indicate that the duration of coupling was shorter in the nontreated control males and increases with the irradiation dose. The total number of mated females per male and the total number of filled spermathecae per male were also influenced by the irradiation dose, being lower for the males treated with 50 Gy with respect to the other groups.

The mean number of matings performed by a male did not show substantial differences at any tested dose compared with the control. The analysis of the mating efficiency (number of mated female/number of coupling) suggests the males irradiated at $50 \mathrm{~Gy}$ to be less efficient relative to the male irradiated at lower doses and the control (Table 8).

\section{Discussion}

The performances of the irradiator used in the study were checked following international standard pro- cedures (IAEA 2004), obtaining consistent results in terms of dose precision and homogeneity in the radiation cylinder unit.

The dosimetry studies performed allowed the production of dose-residual fertility curves for Ae. albopictus male pupae in the range of interest for future evaluation of the optimal radiation dose. This is defined as the best balance between sterility level and sterile male performance (Parker and Mehta 2007). We have no evidence of previous dosimetry studies conducted on Ae. albopictus.

The dose-sterility curves displayed an asymptote, as expected according to the findings reported for other insect species (LaChance and Graham 1984), and the slopes of the regression lines were similar to the one described by Helinski et al. (2006) for An. arabiensis ( $b=-3.95$; see equations 2-4). According to Curtis (1971), the slope described by the dose-sterility curve can be considered a measure of the potential of repairing the damage induced from the $\gamma$ rays. Helinski et al. (2006) stated that plotting fertility on a logarithmic scale against dose provides insight in the nature of dominant lethal mutations. A linear response indicates a "one-hit" relationship (i.e., a large proportion of dominant lethal mutations results from single events in the gametes), whereas departures from linearity indicate a "multi-hit" relationship (gametes carry more than one dominant lethal mutation).

What seems to be peculiar of Ae. albopictus is the low effective sterilizing dose in comparison with other mosquito species. If we consider as convenient the $1.0 \%$ residual fertility level, in the case of Ae. albopictus we calculated a $\gamma$ ray dose in the range 30-35 Gy (depending from the age of the irradiated pupae), whereas $100 \%$ sterility was obtained using $>60 \mathrm{~Gy}$. In the case of An. albimanus, Ali and Rozenboom (1972) using x-rays on 24-h-old pupae obtained $88.7 \%$ sterility with 70 Gy and $100 \%$ sterility with $80 \mathrm{~Gy}$. Considering An. arabiensis exposed as pupae aged $22-26 \mathrm{~h}$ to $\gamma$ rays,

Table 7. Effect of irradiation doses on the longevity (days) of adult males irradiated at different male pupal ages (strain $\mathbf{R}_{\mathrm{F} 23}$ )

\begin{tabular}{|c|c|c|c|c|c|c|c|c|c|}
\hline \multirow{2}{*}{ Pupae age $(\mathrm{h})$} & \multirow{2}{*}{$\gamma$ rays dose $(\mathrm{Gy})$} & \multirow{2}{*}{ Median } & \multirow{2}{*}{ Mean } & \multirow{2}{*}{ SD } & \multicolumn{5}{|c|}{ Log-rank test } \\
\hline & & & & & 0 & 20 & 30 & 40 & 50 \\
\hline \multirow[t]{5}{*}{$16-30$} & 0 & 28.00 & 27.79 & 4.98 & - & $2.10^{*}$ & $3.69 * *$ & $3.58^{* *}$ & $6.51 * *$ \\
\hline & 20 & 31.00 & 25.84 & 8.84 & - & - & 1.52 & 1.27 & $4.12^{* *}$ \\
\hline & 30 & 28.00 & 23.28 & 8.57 & - & - & - & 0.18 & $2.61^{* *}$ \\
\hline & 40 & 28.00 & 23.56 & 8.48 & - & - & - & - & $2.84^{* *}$ \\
\hline & 50 & 22.00 & 21.41 & 7.67 & - & - & - & - & - \\
\hline \multirow[t]{5}{*}{$30-40$} & 0 & 29.00 & 26.07 & 6.79 & - & 0.98 & 0.02 & 0.34 & $4.90 * *$ \\
\hline & 20 & 29.00 & 25.02 & 7.33 & - & - & 0.97 & 0.65 & $3.81 * *$ \\
\hline & 30 & 29.00 & 25.73 & 7.00 & - & - & - & 0.34 & $4.82 * *$ \\
\hline & 40 & 29.00 & 25.84 & 6.86 & - & - & - & - & $4.54^{* *}$ \\
\hline & 50 & 29.00 & 24.10 & 9.37 & - & - & - & - & - \\
\hline
\end{tabular}




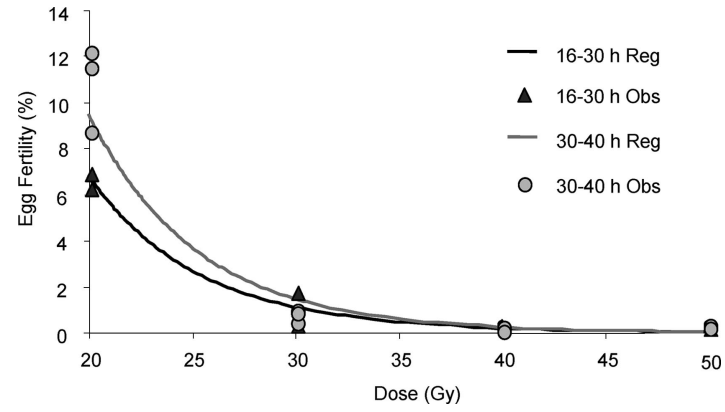

Fig. 3. Dose-response curve of residual fertility for strain $R_{\mathrm{F} 23}$ as a function of the dose received by male pupae aged $16-30 \mathrm{~h}$ or $30-40 \mathrm{~h}$ at irradiation. Lines indicate dose-residual fertility curves, and symbols indicate observed individual values.

Helinski et al. (2006) obtained $98.6 \%$ sterility at the highest tested dose of 100 Gy. In Anopheles gambiae male pupae of different ages, $99.5 \%$ sterility was induced by $\gamma$ radiation of $120 \mathrm{~Gy}$ (Andreasen and Curtis 2005). Anopheles pharoensis male pupae aged $15-20 \mathrm{~h}$ exposed to $\gamma$ rays showed $100 \%$ sterility at $116 \mathrm{~Gy}$ (Abdel-Malek et al. 1967). Irradiating with $\gamma$ rays Anopheles stephensi male pupae aged 4-28 h, Sharma et al. (1978) observed a $99.1 \%$ sterility when using 120 Gy, whereas Andreasen and Curtis (2005) obtained 98.2-98.5\% sterility using the same dose. Two-day-old Culex pipiens molestus male pupae were $99.1 \%$ sterilized when irradiated with $97.3 \mathrm{~Gy}$ of $\gamma$ rays (Sonoda 1972). Culex quinquefasciatus males $\gamma$ radiated as pupae aged $24 \mathrm{~h}$ required $100 \mathrm{~Gy}$ to achieve 99.6 sterility (Smittle et al. 1971a). In a second experiment on the same species, Smittle et al. (1971b) compared $\gamma$ rays with fast neutrons in sterilizing male pupae aged $<24$ $\mathrm{h}$, showing that $73 \mathrm{~Gy}$ of $\gamma$ rays induced $99.8 \%$ sterility, and $20 \mathrm{~Gy}$ of fast neutrons gave $99.5 \%$ sterility. Wijeyaratne et al. (1977) using $\gamma$ radiation on $C x$. quinquefasciatus male pupae of mixed ages obtained $98.5 \%$ sterility with the highest tested dose of $97.3 \mathrm{~Gy}$. Culex tarsalis males exposed to $\gamma$ rays as pupae aged $6-36 \mathrm{~h}$ required $150 \mathrm{~Gy}$ to achieve $98.3 \%$ of sterilization (Darrow 1968). The closest reference data are reported for Ae. aegypti by Hallinan and Rai (1973), in which exposing 1-d-old male pupae obtained $100 \%$ sterility with $70 \mathrm{~Gy}$, not far from our $>60$ Gy for the same sterility level. Weidhaas and Schmidt (1963), irradiating Ae. aegypti male pupa aged $>24 \mathrm{~h}$, obtained $99.9 \%$ sterility with the dose of $78 \mathrm{~Gy}$. The role played by the dose rate of $\gamma$ rays $(\mathrm{Gy} / \mathrm{min})$ on the levels of induced sterility and possible somatic damage still needs to be investigated and clarified in the case of mosquitoes. Our reference rate was $2.2 \mathrm{~Gy} / \mathrm{min} \pm 3.5 \%$, which may be considered at the lower limit of the range reported in similar studies $(1.9-12.0 \mathrm{~Gy} / \mathrm{min}$ ) (Abdel-Malek et al. 1967, Ali and Rozenboom 1972, Darrow 1968, Hallinan and Rai 1973, Helinski et al. 2006, Sharma et al. 1978, Smittle et al. 1971a, Wijeyaratne et al. 1977).

It is well documented that mosquito male pupa age at irradiation (calculated from pupation to irradiation moment) is an important factor, playing a significant role on the sterility level and the quality of produced adults (Abdel-Malek et al. 1967, Dame and Schmidt 1962, Darrow 1968, Wijeyaratne et al. 1977, Andreasen and Curtis 2005, Helinski and Knols 2008).

In our experiment, the statistical comparison between the regression lines calculated for the residual fertility of males treated as pupae of different age found no significant difference between 16- to 30-h and 30 - to 40 -h aged pupae. While in preliminary trials comparing three pupa age classes, we were able to obtain a slight, but not significant, increase in sterility with the discriminant dose of $40 \mathrm{~Gy}$, from $97.77 \%$ in pupae aged $16-24 \mathrm{~h}$, to $99.31 \%$ in pupae aged $24-40 \mathrm{~h}$, to $99.59 \%$ in pupae aged $40-48 \mathrm{~h}$ (Tab. 1).

Adult male longevity determined in laboratory cages was influenced by radiation doses administered to the pupa. In particular, we observed an evident shortening of adult life span at the higher doses tested $(60-80 \mathrm{~Gy})$ and a clear influence of the age of the pupae at radiation on the adult longevity up to the dose of $40 \mathrm{~Gy}$ (Table 2). It remains doubtful whether the laboratory conditions are stressful enough for the adults to evidence possible negative effect of the lower dose radiation.

Abdel-Malek et al. (1966), working with An. pharoensis pupae (males and females) in the range 4.8-68 $\mathrm{Gy}$, found no reduction in longevity in comparison with nontreated pupae. Abdel-Malek et al. (1967), working with An. pharoensis male pupae aged 15-20 h exposed to $\gamma$ ray doses in the range 97-126 Gy, found slight effect on adult longevity (males and females). Cx. pipiens molestus 2-d-old male pupae exposed to $\gamma$ rays in the range 9.7-117 Gy produced adults showing only slightly reduced longevity (Sonoda 1972). Helinski et al. (2006), exposing An. arabiensis pupae aged $22-26 \mathrm{~h}$ to $\gamma$ rays in the range $25-100 \mathrm{~Gy}$, found no clear evidence of dose response in adult male longevity.

Table 8. Mating parameters measured for males irradiated as pupae aged $30-40 \mathrm{~h}$ with 30,40 , and $50 \mathrm{~Gy}(4 \mathrm{males} / 20 \mathrm{females}$ in $30 \times 30 \times 30-c m$ cage)

\begin{tabular}{|c|c|c|c|c|c|c|}
\hline \multirow{2}{*}{$N=2$} & \multicolumn{4}{|c|}{ Dose (Gy) } & \multicolumn{2}{|c|}{ ANOVA } \\
\hline & 0 & 30 & 40 & 50 & $F$ & $P$ \\
\hline Mean duration first 4 couplings (s) & $13.5 \pm 6.7$ & $19.7 \pm 6.9$ & $20.1 \pm 6.2$ & $34.1 \pm 5.1$ & 3.80 & 0.11 \\
\hline No. mated female & $9.0 \pm 2.8$ & $8.5 \pm 0.7$ & $11.0 \pm 1.4$ & $3.5 \pm 2.1$ & 5.42 & 0.07 \\
\hline No. couplings/male & $3.4 \pm 1.6$ & $2.6 \pm 0.5$ & $2.9 \pm 0.9$ & $2.8 \pm 0.2$ & 0.22 & 0.88 \\
\hline No. inseminated females/male & $2.2 \pm 0.7$ & $2.1 \pm 0.2$ & $2.7 \pm 0.3$ & $1.1 \pm 0.8$ & 2.93 & 0.16 \\
\hline No. filled spermathecae/male & $5.1 \pm 1.6$ & $3.5 \pm 0.7$ & $5.5 \pm 0.7$ & $2.0 \pm 1.4$ & 3.74 & 0.12 \\
\hline No. mated female/no. coupling & $0.7 \pm 0.1$ & $0.8 \pm 0.2$ & $1.0 \pm 0.2$ & $0.4 \pm 0.3$ & 2.43 & 0.21 \\
\hline
\end{tabular}


When Ae. albopictus female pupae are irradiated, the adult females show a normal biting behavior, but their fecundity is strongly depressed, resulting in only $1.8 \%$ hatching at $20 \mathrm{~Gy}$ exposure, and complete sterility at $30-40 \mathrm{~Gy}$. Fertility of the few eggs produced by females radiated as pupae with $20 \mathrm{~Gy}$ was also strongly affected, resulting in $23.5 \%$ hatching (Table $6)$. Therefore, the effect of $\gamma$ rays on fecundity and fertility was higher for Ae. albopictus female pupae than for male pupae, as observed in other insect species (Bakry et al. 2005), as well as in other mosquito species (Darrow 1968, Ali and Rozenboom 1972, Sharma et al. 1978). This parameter is of relevance when sexing of male pupae is performed with methods that do not guarantee $100 \%$ efficacy and some sterile females are released as "impurity" together with sterile males. As sterile females lay no eggs, we have no risk of bias in terms of overestimation of sterile male efficacy in the field, as it would be in case the sterile females could have laid sterile eggs.

Helinski et al. (2006) found no significant differences in fecundity of An. arabiensis females mated with males radiated as pupae in the range $25-100 \mathrm{~Gy}$. This parameter has some relevance in field experiments when evaluation of released sterile male efficacy is conducted by collecting eggs to evaluate their fertility level. If fecundity of wild females mated with sterile males is depressed, then a bias in terms of underestimation of the sterile male efficacy may occur.

In our study, we also tested the hypothesis that different Ae. albopictus strains may show a different answer to radiation. Three strains originated from well-separated localities in northern Italy (Pinerolo, Cesena, Rimini) and well adapted to mass rearing artificial condition were considered in the dose-residual fertility study. No difference was found among the tested strains. This is not surprising, as radiosensitivity is considered to show low variation for the same species (Bakri et al. 2005), and previous studies find low genetic variability among Ae. albopictus Italian populations collected in geographically separated areas (Urbanelli et al. 2000).

When investigating the mating capacity of irradiated males in laboratory cage trials, our study suggested the negative impact of radiation at doses higher than $40 \mathrm{~Gy}$, whereas no significant differences were obtained at 30-40 Gy, both in terms of number of mated females/male and number of replenished spermathecae/male.

Notwithstanding the lack of significant differences, the trend of the observations that the mating duration was longer for irradiated males and the efficiency (number of mated female/number of coupling) was lower for irradiated males in comparison with the nontreated males produced strong indications of negative impact on the mating behavior by the radiation treatments even at the lowest doses (Table 8). The relevance of this impact on the mating competitiveness of sterile males remains to be evaluated in large field enclosures and possibly in field studies, as the cage test might not be sensitive enough to detect the impact of deleterious effects of the irradiation with the lower doses.

Few studies on mating capacity of $\gamma$ ray-sterilized mosquitoes pupae are available. Tantawy et al. (1967), working with An. pharoensis, showed that male pupae radiated with 116 Gy produced males with equal mating capacity to normal costrain males.

In this work, we were able to demonstrate that the irradiation of Ae. albopictus male pupae in water medium is a viable and efficient way for obtaining sterile male to be released in SIT programs.

As Helinski and Knols (2008) found that the management of pupae of the malaria vector An. arabiensis for radiating procedures makes no negative impact on adult emergence and behavior, in our study the level of mortality attributable to the transport of the pupae, taken in a film of water for about $3 \mathrm{~h}$, was negligible (data not published).

In the SIT area-wide perspective, the availability of sterile male pupae offers several advantages in comparison with male adults, such as the easier handling of the pupae (small containers with little water), their high resistance to the stress caused by manipulation during the treatment process and to desiccation (up to $2 \mathrm{~d}$ at $26^{\circ} \mathrm{C}$ and $87 \% \mathrm{RH}$, Hien 1975), the possibility to release them in natural breeding sites, and/or to provide them with a carbohydrate energy source at the releasing site.

\section{Acknowledgments}

We thank Mark Q. Benedict and Andrew Parker for their help in the manuscript revision, valuable support, and suggestions. This work was supported by a grant from the EmiliaRomagna Regional Bureau-Public Health Department.

\section{References Cited}

Abbott, W. S. 1925. A method of computing the effectiveness of an insecticide. J. Econ. Entomol. 18: 265-267.

Abdel-Malek, A. A., A. O. Tantawy, and A. M. Wakid. 1966. Studies on the eradication of Anopheles pharoensis Theobald by the sterile-male technique using Cobalt- 60 . I. Biological effects of $\gamma$ radiation on the different developmental stages. J. Econ. Entomol. 59: 672-678.

Abdel-Malek, A. A., A. Q. Tantawy, and A. M. Wakid. 1967. Studies on the eradication of Anopheles pharoensis by the sterile-male technique using cobalt-60. III. Determination of the sterile dose and its biological effects on different characters related to "fitness" components. J. Econ. Entomol. 60: 20-23.

Ali, S. R., and L. E. Rozenboom. 1972. Observation on sterilization of Anopheles (C.) albimanus Wiedemann by Xirradiation. Mosq. News 32: 574-579.

Andreasen, M. H., and C. F. Curtis. 2005. Optimal life stage for radiation sterilization of Anopheles males and their fitness for release. Med. Vet. Entomol. 19: 238-244.

Angelini, R., A. C. Finarelli, P. Angelini, C. Po, K. Petropulacos, P. Macini, C. Fiorentini, C. Fortuna, G. Venturi, R. Romi, G. Majori, L. Nicoletti, G. Rezza, and A. Cassone. 2007. An outbreak of Chikungunya fever in the province of Ravenna, Italy. Euro Surveill. 12(36): pii-3260. (http:// www.eurosurveillance.org).

Anonymous. 1975. Oh, New Delhi; oh, Geneva. Nature 256: 355-357. 
Asman, S. M., P. T. McDonald, and T. Prout. 1981. Field studies of genetic control systems for mosquitoes. Annu. Rev. Entomol. 26: 289-318.

Bakri, A., N. Heather, J. Hendrichs, and I. Ferris. 2005. Fifty years of radiation biology in entomology: lessons learned from IDIDAS. Ann. Entomol. Soc. Am. 98: 1-12.

Barry, J. D., T. Blessinger, and J. G. Morse. 2004. Recapture of sterile Mediterranean fruit flies (Diptera: Tephritidae) in California's preventative release programme. J. Econ. Entomol. 97: 1554-1562.

Baumhover, A. H., A. J. Graham, B. A. Bitter, D. E. Hopkins, W. D. New, F. H. Dudley, and R. C. Bushland. 1955. Screw-worm control through release of sterilized flies. J. Econ. Entomol. 48: 462-466.

Bellini, R., A. Medici, M. Carrieri, M. Calvitti, and U. Cirio. 2004. Applicazione della tecnica del maschio sterile nella lotta contro Aedes albopictus in Italia: ottimizzazione delle fasi di allevamento massale e sessaggio, vol. II, pp. 993-998. In Proceedings of the National Congress of Entomology, 10 -15 June 2002, Catania, Litografia Tipografia Polaris, Sondrio.

Bellini, R., M. Calvitti, A. Medici, M. Carrieri, G. Celli, and S. Maini. 2007. Use of the sterile insect technique against Aedes albopictus in Italy: first results of a pilot trial, pp. 505-515. In M.J.B. Vreysen, A. S. Robinson, and J. Hendrichs (eds.), Area-wide control of insect pests: from research to field implementation. Springer, Dordrecht, The Netherlands.

Bonilauri, P., R. Bellini, M. Calzolari, R. Angelini, L. Venturi, F. Fallacara, P. Cordioli, P. Angelini, C. Venturelli, G. Merialdi, and M. Dottori. 2008. Chikungunya virus in Aedes albopictus, Italy. Emerg. Infect. Dis. 14: 852-853.

Carrieri, M., R. Bellini, S. Maccaferri, L. Gallo, S. Maini, and G. Celli. 2008. Tolerance thresholds for Aedes albopictus and Aedes caspius in Italian urban areas. J. Am. Mosq. Control Assoc. 24: 377-386.

Curtis, C. F. 1971. Induced sterility in insects. Adv. Reprod. Physiol. 5: 120-165.

Curtis, C. F. 2006. Review of previous applications of genetics to vector control, pp. 33-44. In B.G.J. Knols and C. Louis (eds.), Bridging laboratory and field research for genetic control of disease vectors: Wageningen UR Frontis Series. Springer, Wageningen, The Netherlands.

Dame, D. A., and C. H. Schmidt. 1962. The importance of competitiveness of radiosterilized males in mosquitocontrol programs. NJ Mosq. Exterm. Assoc. 49: 165-168.

Darrow, D. I. 1968. The effect of $\gamma$ irradiation on reproduction and life span of the mosquito Culex tarsalis Coquillett. Mosq. News 28: 21-24.

ECDC Technical Report. 2009. Development of Aedes albopictus risk maps (by E.-J. Scholte and F. Schaffner). (http:/ / ecdc.europa.eu/en/files/pdf/Publications/0905 TER_Development_of_Aedes_albopictus_risk_maps.pdf).

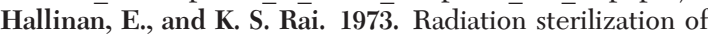
Aedes aegypti in nitrogen and implications for sterile male technique. Nature 244: 368-369.

Hawley, W. A. 1988. The biology of Aedes albopictus. J. Am. Mosq. Control Assoc. Suppl. 1: 1-39.

Helinski, M.E.H., and B.G.J. Knols. 2008. Mating competitiveness of males Anopheles arabiensis mosquitoes irradiated with a partially or fully sterilizing dose in small and large laboratory cages. J. Med. Entomol. 45: 698-705.

Helinski, M.E.H., A. G. Parker, and B.G.J. Knols. 2006. Radiation-induced sterility for pupal and adult stages of the malaria mosquito Anopheles arabiensis. Malar. J. 5: 41.

Hien, D. S. 1975. Biology of Aedes aegypti (L.,176) and Aedes albopictus (Skuse, 1895) (Diptera Culicidae). III.
Effect of certain environmental conditions on the development of larvae and pupae. Acta Parasit. Polonica 23: 553-568.

Honório, N. A., W. da Costa Silva, P. J. Leite, J. Monteiro Gonçalves, L. P. Lounibos, and R. L. de-Oliveira. 2003. Dispersal of Aedes aegypti and Aedes albopictus (Diptera: Culicidae) in an urban endemic dengue area in the State of Rio de Janeiro, Brazil. Mem. Inst. Oswaldo Cruz 98: 191-198.

IAEA. 2004. Gafchromic dosimetry system for SIT. (http:// www-naweb.iaea.org/nafa/ipc/public/Dosimetry SOP v10b.pdf).

Jones, J. C. 1968. A study on the fecundity of male Aedes aegypti. J. Insect Physiol. 19: 435-439.

Jones, J. C., and R. E. Wheeler. 1965. Studies on spermathecal filling in Aedes aegypti (Linnaeus). II. Experimental. Biol. Bull. Wood Hole 129(3): 532-545.

LaChance, L. E., and C. K. Graham. 1984. Insect radiosensitivity: dose curves and dose-fractionation studies of dominant lethal mutations in the mature sperm of 4 insect species. Mutat. Res. 127: 49-59.

Medici, A., M. Carrieri, E.-J. Scholte, and R. Bellini. 2000. Studies aimed to set-up a sterilization insect technique programme against Aedes albopictus Skuse, pp. 160-165. In Proceedings, 13th European Meeting of the Society for Vector Ecology, 24-29 September 2000, Belek, Turkey.

Parker, A., and K. Mehta. 2007. Sterile insect technique: a model for dose optimization for improved sterile insect quality. Fl. Entomol. 90: 88-95.

Sabatini, A., V. Raineri, G. Trovato, and M. Coluzzi. 1990. Aedes albopictus in Italia e possibile diffusione della specie nell'area mediterranea. Parassitologia 32: 301-304.

Sharma, V. P., R. K. Razdan, and M. A. Ansari. 1978. Anopheles stephensi: effect of $\gamma$-radiation and chemosterilants on the fertility and fitness of males for sterile male releases. J. Econ. Entomol. 71: 449-452.

Smittle, B. J., P. A. Cannarozzi, and J. B. Gahan. 1971a. $\gamma$ Irradiation of eggs, larvae, pupae, and adults of Culex pipiens quinquefasciatus Say. Mosq. News 31: 102-105.

Smittle, B. J., G. C. LaBrecque, and R. S. Patterson. 1971b. Comparison of fast neutrons and $\gamma$ rays in producing sterility in Culex pipiens quinquefasciatus Say. Mosq. News 31: $477-478$.

Sonoda, H. 1972. The effect of $\gamma$ irradiation on fertility and mating competitiveness of the mosquito, Culex pipiens molestus F. (Diptera: Culicidae). Appl. Entomol. Zool. 7: 103-108.

Takagi, M., Y. Tsuda, and Y. Wada. 1995. Temporal and spatial distribution of released Aedes albopictus (Diptera: Culicidae) in Nagasaki, Japan. Jpn. J. San. Zool. 46: 223228.

Tantawy, A. O., A. A. Abdel-Malek, and A. M. Wakid. 1967. Studies on the eradication of Anopheles pharoensis by the sterile-male technique using cobalt-60. IV. Mating behavior and its frequency in the sterilized mosquitoes. J. Econ. Entomol. 60: 23-26.

Urbanelli, S., R. Bellini, M. Carrieri, P. Sallicandro, and G. Celli. 2000. Population structure of Aedes albopictus (Skuse): the mosquito which is colonizing Mediterranean countries. Heredity 84: 331-337.

Vreysen, M.J.B., K. M. Saleh, M. Y. Ali, A. M. Abdulla, Z.-R. Zhu, K. G. Juma, V. A. Dyck, A. R. Msangi, P. A. Mkonyi, and H. U. Feldmann. 2000. Glossina austeni (Diptera: Glossinidae) eradicated on the island of Unguja, Zanzibar, using the sterile insect technique. J. Econ. Entomol. 93: 123-135. 
Weidhaas, D. E., and C. H. Schmidt. 1963. Mating ability of male mosquitoes, Aedes aegypti (L.) sterilized chemically or by $\gamma$ radiation. Mosq. News 23: 32-34.

Whitten, M. J., and G. G. Foster. 1975. Genetical methods of pest control. Annu. Rev. Entomol. 20: 461-476.

Wijeyaratne, P. M., D. E. Weidhaas, B. J. Smittle, and M. D. Boston. 1977. Sterilization of male Culex quinquefascia- tus: evaluation of five insect chemosterilants and $\gamma$ irradiation. Mosq. News 37: 1-5.

Wyss, J. H. 2000. Screw-worm eradication in the Americas. Ann. NY Acad. Sci. 916: 186-193.

Received 12 November 2009; accepted 24 March 2010. 